\title{
OPEN GAN inversion method of an initial in situ stress field based on the lateral stress coefficient
}

\author{
Li Qian ${ }^{1}$, Tianzhi Yao ${ }^{1}$, Zuguo Mo ${ }^{1 凶}$, Jianhai Zhang ${ }^{1}$, Yonghong $\mathrm{Li}^{2}$, Ru Zhang ${ }^{1}$, Nuwen $\mathrm{Xu}^{1}$ \& \\ Zhiguo $\mathrm{Li}^{2}$
}

The initial in situ stress field influences underground engineering design and construction. Since the limited measured data, it is necessary to obtain an optimized stress field. Although the present stress field can be obtained by valley evolution simulation, the accuracy of the ancient stress field has a remarkable influence. This paper proposed a method using the generative adversarial network (GAN) to obtain optimized lateral stress coefficients of the ancient stress field. A numerical model with flat ancient terrain surfaces is established. Utilizing the nonlinear relationship between measured stress components and present burial depth, lateral stress coefficients of ancient times are estimated to obtain the approximate ancient stress field. Uniform designed numerical tests are carried out to simulate the valley evolution by excavation. Coordinates, present burial depth, present lateral stress coefficients and ancient regression factors of lateral stress coefficients are input to GAN as real samples for training, and optimized ancient regression factors can be predicted. The present stress field is obtained by excavating strata layers. Numerical results show the magnitude and distribution law of the present stress field match well with measured points, thus the proposed method for the stress field inversion is effective.

As a foundation for underground engineering design and stability analysis ${ }^{1}$, the initial in situ stress field of a rock mass refers to the natural stress state of the rock mass before engineering construction ${ }^{2}$, which has a great effect on the deformation and failure of the rock mass. To ensure the construction safety of engineering, it is necessary to obtain an optimized initial in situ stress field for deep-buried underground engineering ${ }^{3}$. The formation of an in situ stress field is a complex process that is affected by topography, geology, rock behavior, tectonic evolution and other factors ${ }^{4-6}$. Therefore, it is nearly impossible to obtain an optimized in situ stress field for every space point in underground engineering, but it is still important to obtain a more optimized initial stress field by various inversion methods.

In situ stress can be obtained directly by field in situ stress measurement methods, such as strain relief, acoustic emission, borehole cores, and hydraulic fracturing tests ${ }^{7-11}$. However, due to limited funding and testing technology, as well as complex geological tectonic and steep terrain conditions, it is hard to obtain a large number of in situ stress measurement results ${ }^{12,13}$. Moreover, the measured stress can only reveal the distribution characteristics of the stress field in a local area. Therefore, it is necessary to use an efficient back analysis method combined with advanced numerical simulation to derive a reasonable and applicable initial stress field based on limited measurement results and engineering geological data to meet the needs of engineering ${ }^{14-20}$.

(1) In the multiple linear regression method ${ }^{21}$, a numerical model based on the distribution of rock layers and topographic features is established. By considering gravity and several tectonic stress fields, a multiple linear regression equation is constructed. The solution of the equation gives regression factors for stress fields. The initial stress field is a linear combination of these stress fields multiplied by the corresponding regression factors ${ }^{22-24}$. This method is convenient and efficient, and the solution is unique, suitable for rock masses with simple geological conditions and has been widely used ${ }^{25}$. However, for engineering projects with complex geological conditions, in situ stress values obtained by the superposition of regression factors often differ greatly from the measured values. In addition, this method linearly superimposes different

\footnotetext{
${ }^{1}$ State Key Laboratory of Hydraulics and Mountain River Engineering, College of Water Resources and Hydropower, Sichuan University, Chengdu 610065, China. ${ }^{2}$ Power China Chengdu Engineering Corporation Limited, Chengdu 610072, China. ${ }^{\square}$ email: mozuguo@163.com
} 
in situ stress fields, but in deep-buried underground engineering, the relationship between the in situ stress and burial depth is not linear.

(2) The boundary load adjustment method ${ }^{26,27}$ repeatedly adjusts the calculated boundary load of the numerical model so that the calculated stress values under certain working conditions are close to the measured values. The initial in situ stress obtained by this method can be highly optimized for a specific space point but can hardly fit all measured points. In addition, there is no unique solution for this method, and the trial solution process has no rules to follow and can be time-consuming.

(3) The displacement back analysis method ${ }^{28}$ uses the assumed in situ stress field and rock mass mechanical parameters to calculate the displacement of the engineering excavation through numerical simulation. The mechanical parameters of the rock mass are adjusted until the calculated displacement is consistent with the measured displacement. Then, the secondary stress field is obtained ${ }^{29,30}$. However, this method is only applicable to underground engineering during construction and cannot be applied in the engineering design stage $\mathrm{e}^{31}$.

(4) The valley evolution method ${ }^{32,33}$ uses layered excavation of ancient strata to simulate the formation process of the present topography and uses the lateral stress coefficient to indicate the variation in the stress field, thus obtaining the present in situ stress field. However, since large underground engineering stresses are affected by tectonic stress, it is difficult to determine the lateral stress coefficient, and because the lateral stress coefficient is not a constant value at various depths, this method can result in a large error in the initial in situ stress field inversion.

(5) Artificial intelligence combined with the above methods $s^{34-36}$ can improve the efficiency and accuracy of in situ stress inversion. It can simulate the physiological mechanism of the human brain through a large number of neurons to realize intelligent information processing ${ }^{37}$. Artificial intelligence has remarkable advantages in nonlinear analysis and fuzzy recognition ${ }^{38-40}$. Commonly used artificial intelligence methods include neural networks ${ }^{34}$, genetic algorithms ${ }^{41}$, and gray theories ${ }^{2}$. These artificial intelligence methods usually aim at inversion of stress at measured points, not the global stress distribution, which results in good agreement at the measured points but uncertain accuracy elsewhere.

In this paper, a 3D numerical model of the Shuangjiangkou underground hydropower station in ancient times is established, which is used to invert initial in situ stress field. According to measured point data, the lateral stress coefficients of stress components in ancient times are estimated, and multiple combinations of stress components with different lateral stress coefficients are established by a uniform design test. Generative adversarial network (GAN) can automatically establish high-dimensional and global probability distribution of variables by confront training, and can generate new data samples according to the distribution of real data, which can improve the accuracy of rock mechanical parameters and models. Based on the nonlinear analysis of the GAN, two regression factors governing the distribution law of optimized lateral stress coefficients of each stress component in ancient times were determined. After GAN prediction of 12 regression factors for six stress components, optimized lateral stress coefficients are determined. By built model of ancient planation surface with no undulations, the ancient stress field can be reconstructed using the optimized lateral stress coefficients. Then, strata are excavated by layers to simulate valley evolution, and the final stress result represents the present in situ stress field and distribution law. Through comparison and verification with measurement points, this inversion method of initial in situ stress is found to be feasible and suitable for deep buried large underground engineering.

\section{GAN inversion method for initial in situ stress field}

The stress field in deep-cut valley area evolves from an ancient regional stress field, accompanied by river valley erosion, surface denudation and other geological effects to shape the valley slope in a long-term unloading process, prompting the rock mass to constantly adjust stress, strain and energy to form a new local stress field ${ }^{42}$. Therefore, top-down excavation of the ancient strata is used to simulate the gradual formation of the river valley geomorphic characteristics and the release of stress in the inversion of the present in situ stress field. The ancient strata denudation process is shown in Fig. 1, and the following assumptions are made about ancient surface and geological formations ${ }^{43,44}$.

(1) The ancient surface is a planation surface with no obvious undulations.

(2) The ancient stress field consists mainly of a self-gravity stress field and a tectonic stress field, and tectonic movement was completed in the ancient period.

(3) The present in situ stress field evolved from an ancient stress field and was gradually formed by geological effects such as surface denudation and river erosion.

Inversion of the ancient stress field based on the lateral stress coefficient. In recent years, a method using lateral stress coefficients to inverse in situ stress fields has been proposed and developed ${ }^{32,33,42}$ and is expressed as

$$
\sigma_{i}(x, y, z)=k_{i} \gamma H
$$

where $\sigma_{1}-\sigma_{6}$ are stress components $\sigma_{x}, \sigma_{y}, \sigma_{z}, \tau_{y z}, \tau_{z x}$ and $\tau_{x y} . k_{i}$ is the lateral stress coefficient for the six stress components. $H$ is burial depth. $\gamma$ is bulk density.

However, the present stress field is affected by topographical fluctuations and rock mass mechanical properties, leading to the in situ stress coefficient varying greatly in different places ${ }^{31}$. In ancient times, the topography 


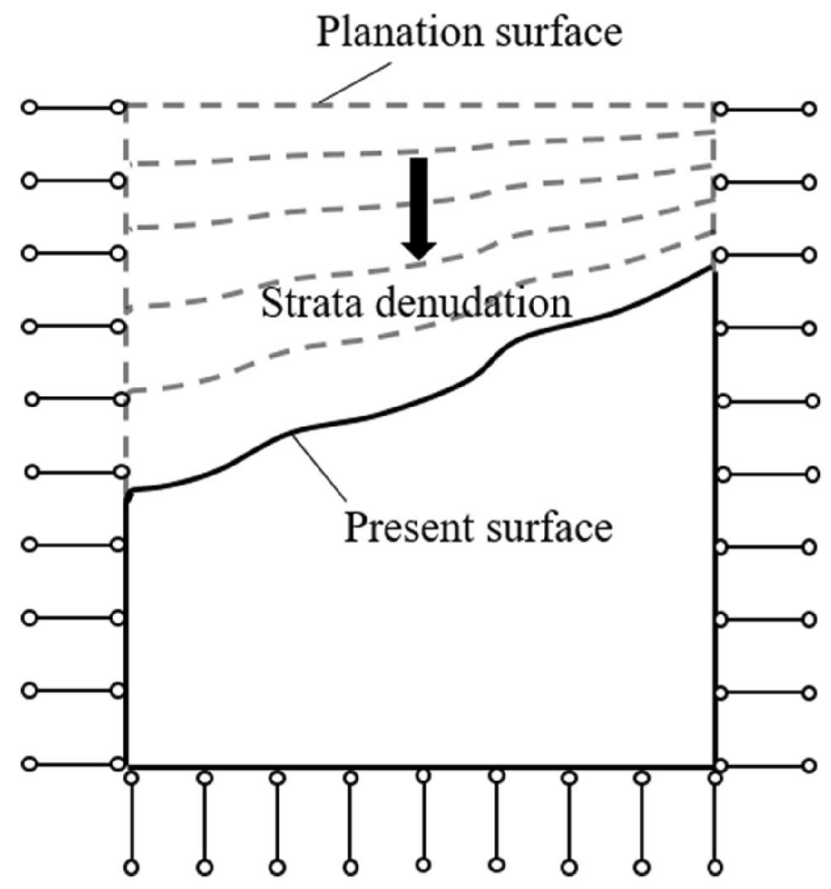

Figure 1. Schematic diagram of ancient strata denudation process.

and geomorphology had small fluctuations, and the geological structure was simple. Therefore, utilizing lateral stress coefficients to invert the ancient stress field is more suitable.

Many scholars ${ }^{25,37}$ have considered that lateral stress coefficients are a certain value at each place in a rock mass, which means that stress components increase linearly as burial depth increases. However, for deep buried engineering, the lateral stress coefficient is found not to be linear with burial depth ${ }^{45}$. Based on global measured in situ stress data, Brown and Hoek ${ }^{45}$ found that the relationship between the lateral stress coefficient and the burial depth is

$$
\frac{100}{H}+0.3 \leq \frac{\sigma_{H}+\sigma_{h}}{2 \sigma_{v}} \leq \frac{1500}{H}+0.5
$$

where $\sigma_{H}, \sigma_{h}$ and $\sigma_{v}$ are the maximum principal stress, minimum principal stress on the horizontal plane and vertical stress, respectively.

Based on the statistical analysis of lateral stress coefficients of different rock masses in mainland China, Jing Feng ${ }^{46}$ reached conclusions similar to the ones of Eq. (2). Therefore, the relationship between the lateral stress coefficients and burial depth is

$$
k_{i}=\frac{a_{i}}{H}+b_{i}
$$

where $a_{i}$ and $b_{i}$ are regression factors.

Based on Eq. (3) and measured stresses in engineering, approximate lateral stress coefficients $k_{i}$ of different stress components can be obtained. Introducing $k_{i}$ to Eq. (1), an approximate ancient stress field can be obtained.

Inversion of the present in situ stress field based on GAN. Based on the approximate ancient stress field, numerical simulation can be used to excavate the ancient strata layer by layer to obtain the present stress field. Since the ancient stress field is approximately estimated, there may be a large error in obtaining the present stress field. To solve this problem, this paper introduces the generative adversarial network (GAN) to fine-tune lateral stress coefficients in ancient times to optimize the present in situ stress field to meet the demand of engineering analysis.

GAN is a generative model proposed by Goodfellow et al. $^{47}$, and further developed by Mirza et al. ${ }^{48}$, Odena et al. ${ }^{49}$ and Reed et al. ${ }^{50}$. Its basic thought is inspired by a minimax two-player game, and is widely used in artificial intelligence models, which show high learning and association capabilities and distributed processing capabilities to solve nonlinear problems. GAN consists of a generator and a discriminator trained on confrontational learning mechanism, as shown in Fig. 2. The purpose of GAN is to estimate the potential distribution of existing data and generate new data samples from the same distribution by a generator $G$ which transforms the random variables $z$ into the data that can be faked by continuously learning the probability distribution of real data. The discriminator $D$ is a binary classifier that discriminates whether the input data is real or generated data samples. The two networks are enhanced simultaneously by competing with each other during training, so that the two networks constitute a dynamic game process, until Nash equilibrium ${ }^{51}$ is achieved. Both the generator and the 


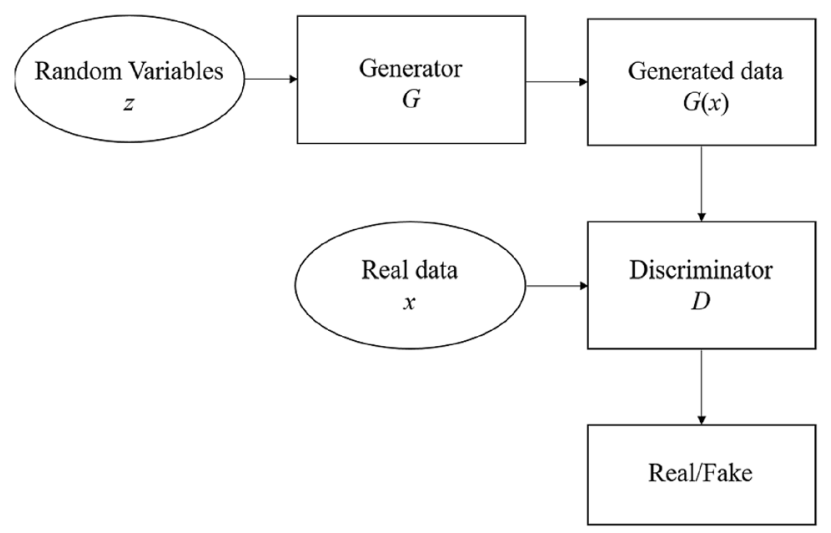

Figure 2. Calculation process of GAN.

discriminator can be designed in conjunction with the current deep neural networks ${ }^{52}$. The calculated process of GAN can be summarized as a binary minimax game, and the objective function can be defined as:

$$
\min _{G} \max _{D} V(D, G)=E_{x \sim P_{\text {data }(x)}}[\lg D(x)]+E_{z \sim P_{g(z)}}[\lg (1-D(G(z)))]
$$

where $V(D, G)$ is the cross-entropy loss of two classifications, $P_{\text {data }}(x)$ is the real data distribution, $P_{g}(z)$ is the random variables distribution, $G(z)$ is samples generated by the generator based on the random variables, and $E(\cdot)$ means the calculated expected value. The global optimal solution is reached when $P_{\text {data }}=P_{g}$. For GAN, the loss function of generator and discriminator are expressed as $\log (D(G(z)))$ and $\log (D(x))+\log (1-D(G(z)))$.

In this paper, deep learning is carried out on the distribution of the lateral stress coefficient based on the superiority of GAN data enhancement. The basic process of using GAN to analyze the lateral stress coefficients is as follows.

(1) From field survey data, the obtained stress values of the measured points are statistically analyzed, and the effective measured points are selected to determine the approximate lateral stress coefficients by Eq. (3).

(2) Based on a uniform design test, multiple ancient stress fields with different values of $a_{i}$ and $b_{i}$ can be designed for a given floating range of $a_{i}$ and $b_{i}$ in Eq. (3).

(3) According to multiple ancient stress fields, strata excavation is carried out using FLAC3D to obtain multiple present initial stress fields, from which lateral stress coefficients under the present burial depth are determined.

(4) The coordinates of the measurement point, present burial depth, present lateral stress coefficient and regression factors in ancient times are regarded as real data sample. After data normalization, the data sample are input into the GAN for training.

(5) After training in GAN, regression factors $a_{i}$ and $b_{i}$ of the optimized ancient lateral stress coefficients can be obtained. Then, the optimized ancient stress field is constructed by Eq. (1).

(6) After excavating the optimized ancient stress field, the optimized present initial stress field can be obtained.

For the selection of $a_{i}$ and $b_{i}$ values, many scholars ${ }^{25,53-56}$ use orthogonal experiments. There are six pairs of regression factors $a_{i}$ and $b_{i}$ for six stress components. According to the principle of orthogonal experiments, $(6 \times 2)^{2}=144$ combinations need to be designed for numerical calculation, which can lead to an excessive number of orthogonal tests and is rather time-consuming. Therefore, it is more appropriate to use a uniform design test instead of an orthogonal test ${ }^{22,57}$. The advantage of the uniform design can greatly reduce the number of tests and keep training samples uniformly dispersed. In the uniform design test, multiple combinations with different values of $a_{i}$ and $b_{i}$ can be designed. The parameters of the measured points under different combinations of $a_{i}$ and $b_{i}$ are

$$
\begin{aligned}
\mathbf{x} & =\left[x_{1}, x_{2}, \ldots x_{n}\right]^{T} \\
\mathbf{y} & =\left[y_{1}, y_{2}, \ldots y_{1 n}\right]^{T} \\
\mathbf{H}^{\mathbf{p}} & =\left[H_{1}^{p}, H_{2}^{p}, \ldots H_{n}^{p}\right]^{T}
\end{aligned}
$$




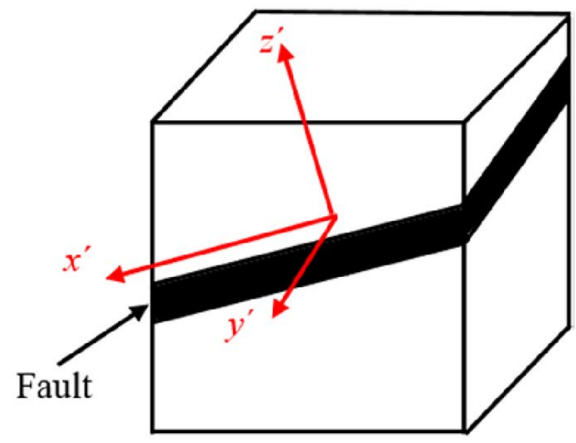

(a) Composite element

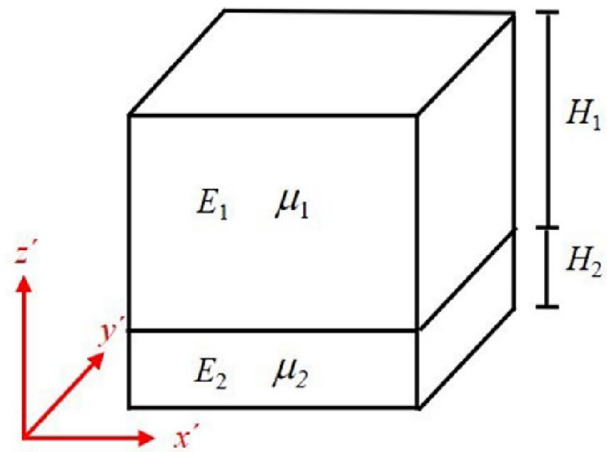

(b) Equivalent element

Figure 3. Schematic diagram of fault cutting rock mass element.

$$
\begin{gathered}
\mathbf{k}_{\mathbf{j}}=\left[\begin{array}{c}
k_{11}, k_{12}, k_{13}, k_{14}, k_{15}, k_{16} \\
k_{21}, k_{22}, k_{23}, k_{24}, k_{25}, k_{26} \\
\vdots \\
k_{\mathrm{n} 1}, k_{\mathrm{n} 2}, k_{\mathrm{n} 3}, k_{\mathrm{n} 4}, k_{\mathrm{n} 5}, k_{\mathrm{n} 6}
\end{array}\right] \\
\mathbf{a}_{\mathbf{j}}=\left[\begin{array}{c}
a_{11}, a_{12}, a_{13}, a_{14}, a_{15}, a_{16} \\
a_{21}, a_{22}, a_{23}, a_{24}, a_{25}, a_{26} \\
\vdots \\
a_{n 1}, a_{n 2}, a_{n 3}, a_{n 4}, a_{n 5}, a_{n 6}
\end{array}\right] \\
\mathbf{b}_{\mathbf{j}}=\left[\begin{array}{c}
b_{11}, b_{12}, b_{13}, b_{14}, b_{15}, b_{16} \\
b_{21}, b_{22}, b_{23}, b_{24}, b_{25}, b_{26} \\
\vdots \\
b_{n 1}, b_{n 2}, b_{n 3}, b_{n 4}, b_{n 5}, b_{n 6}
\end{array}\right]
\end{gathered}
$$

where $\mathbf{x}$ and $\mathbf{y}$ are the coordinate vectors in the horizontal plane of the measured points. $n$ is the number of measured points. $\mathbf{H}^{\mathrm{P}}$ is the burial depth vector of the measured points at present. $\mathbf{k}_{\mathbf{j}}$ is the lateral stress coefficient matrix of the measured points at present and $j$ is the number of uniform design tests. $\mathbf{a}_{\mathbf{j}}$ and $\mathbf{b}_{\mathbf{j}}$ are regression factors matrices of stress components $\sigma_{x}, \sigma_{y}, \sigma_{z}, \tau_{y z}, \tau_{z x}$ and $\tau_{x y}$ of measured points in ancient times.

After each uniform design test, the training of the GAN can be carried out. The real data sample input to GAN can be expressed as:

$$
\mathbf{P}=\left[\begin{array}{c}
\mathbf{x}, \mathbf{y}, \mathbf{H}^{\mathbf{p}}, \mathbf{k}_{\mathbf{1}}, \mathbf{a}_{\mathbf{1}}, \mathbf{b}_{\mathbf{1}} \\
\mathbf{x}, \mathbf{y}, \mathbf{H}^{\mathbf{p}}, \mathbf{k}_{\mathbf{2}}, \mathbf{a}_{2}, \mathbf{b}_{2} \\
\vdots \\
\mathbf{x}, \mathbf{y}, \mathbf{H}^{\mathbf{p}}, \mathbf{k}_{\mathbf{j}}, \mathbf{a}_{\mathbf{j}}, \mathbf{b}_{\mathbf{j}}
\end{array}\right]
$$

After training, input the data of measured points to GAN, the optimized $a_{i}$ and $b_{i}$ values can be obtained. The optimized ancient stress field can be calculated by Eq. (3), and the present stress field can then be obtained after a nonlinear elastic-plastic excavation simulation.

Equivalent mechanical parameters of faults. The parameters between the fault and the rock mass are quite different. If the influence of the fault is not considered in the inversion of the present stress field, it causes a large error in the result ${ }^{58}$. Therefore, the parameters of faults should be assigned to the corresponding element before simulating the excavation of ancient strata. Faults and underground caverns do not usually intersect in an orthogonal form and are often simplified into thin elements in numerical simulation analysis. This method of treating faults may bring difficulties in the mesh generation of models due to the limited thickness and complicated intersection relationship of faults.

In this paper, the rock mass is divided into hexahedron elements. Due to the existence of faults, some rock mass elements are cut by faults. These elements contain both rock masses and faults, forming composite elements, as shown in Fig. 3a. For one element, only a set of mechanical parameters can be assigned, so the mechanical parameters of composite elements with both rock masses and faults need to be equalized ${ }^{59}$. It is assumed that the composite element is a transversely isotropic material in the local coordinate system $\left(x^{\prime} y^{\prime} z^{\prime}\right)$ established on 
the fault plane. The composite element is simplified into an equivalent element distributed in layers, and the parameters are shown in Fig. 3 b. $H_{k}$ is the layer thickness, which can be expressed as

$$
H_{k}=V_{k} / A
$$

where subscript $k$ equals 1 or 2 , representing the parameters of the rock mass and fault, respectively. $V_{k}$ is volume of rock mass or fault. $A$ is the area of the contact surface between the rock mass and the fault.

For the $z^{\prime}$ direction, the deformation and stress of the equivalent element are

$$
\left\{\begin{array}{l}
\bar{\sigma}_{v}=\sigma_{v 1}=\sigma_{v 2} \\
\Delta l=\frac{\sigma_{v 1}}{E_{1}} H_{1}+\frac{\sigma_{v 2}}{E_{2}} H_{2}=\frac{\sigma_{v}}{\bar{E}_{v}}\left(H_{1}+H_{2}\right)
\end{array}\right.
$$

where $\tilde{\sigma}_{v}, \sigma_{v 1}$ and $\sigma_{v 2}$ are the stress applied in the equivalent element, rock mass and fault, respectively, in the $z^{\prime}$ direction. $\bar{E}_{v}$ is the equivalent elastic modulus in $z^{\prime}$ direction.

Based on Eq. (13), the equivalent elastic modulus in the $z^{\prime}$ direction is

$$
\bar{E}_{v}=\left(H_{1}+H_{2}\right) /\left(\frac{H_{1}}{E_{1}}+\frac{H_{2}}{E_{2}}\right)
$$

For the $x^{\prime}$ and $y^{\prime}$ directions, assuming that the elongation of the rock mass and fault in the equivalent element are equal, then

$$
\left\{\begin{array}{l}
\bar{\varepsilon}_{h}=\varepsilon_{h 1}=\varepsilon_{h 2} \\
\bar{\sigma}_{h}\left(H_{1}+H_{2}\right)=\sigma_{h 1} H_{1}+\sigma_{h 2} H_{2}
\end{array}\right.
$$

where $\bar{\varepsilon}_{h}, \varepsilon_{h 1}$ and $\varepsilon_{h 2}$ are the strain in the equivalent element, rock mass and fault in the $x^{\prime}$ and $y^{\prime}$ directions, respectively. $\bar{\sigma}_{h}, \sigma_{h 1}$ and $\sigma_{h 2}$ are the stresses applied in the equivalent element, rock mass and fault in the $x^{\prime}$ and $y^{\prime}$ directions, respectively.

Equation (15) can be written as

$$
\bar{E}_{h} \bar{\varepsilon}_{h}\left(H_{1}+H_{2}\right)=E_{1} \varepsilon_{h 1} H_{1}+E_{2} \varepsilon_{h 2} H_{2}
$$

where $\bar{E}_{h}$ is the equivalent elastic modulus in the $x^{\prime}$ and $y^{\prime}$ directions.

Based on Eqs. (15) and (16), the equivalent elastic modulus is

$$
\bar{E}_{h}=\frac{E_{1} H_{1}+E_{2} H_{2}}{H_{1}+H_{2}}
$$

Combining Eqs. (15) and (17), the equivalent Poisson's ratio $\bar{\mu}$ can be expressed as

$$
\begin{aligned}
\bar{\mu} & =\frac{\bar{\varepsilon}_{h}}{\bar{\varepsilon}_{v}}=\frac{\bar{\sigma}_{h}}{\bar{E}_{h}} \cdot \frac{1}{\bar{\varepsilon}_{v}}=\frac{\sigma_{h 1} H_{1}+\sigma_{h 2} H_{2}}{\bar{E}_{h}\left(H_{1}+H_{2}\right)} \cdot \frac{1}{\bar{\varepsilon}_{v}} \\
& =\frac{\mu_{1} E_{1} \varepsilon_{v 1} H_{1}+\mu_{2} E_{2} \varepsilon_{v 2} H_{2}}{\bar{E}_{h}\left(H_{1}+H_{2}\right)} \cdot \frac{1}{\bar{\varepsilon}_{v}} \\
& =\frac{\mu_{1} \sigma_{v 1} H_{1}+\mu_{2} \sigma_{v 2} H_{2}}{\bar{E}_{h}\left(H_{1}+H_{2}\right)} \cdot \frac{\bar{E}_{v}}{\bar{\sigma}_{v}} \\
& =\frac{\mu_{1} H_{1}+\mu_{2} H_{2}}{H_{1}+H_{2}} \cdot \frac{\bar{E}_{v}}{\bar{E}_{h}}
\end{aligned}
$$

\section{Project overview and in situ stress measurement analysis}

The Shuangjiangkou hydropower station is located on the Dadu River in western Sichuan Province, China. The diversion and power generation structures of the hydropower station are arranged on the left bank of the mountain. The length of the 3D numerical model is $878.14 \mathrm{~m}$ in the $X$ direction and $950 \mathrm{~m}$ in the $Y$ direction, as shown in Fig. 4. The $X$ direction is $\mathrm{N} 170^{\circ} \mathrm{E}$ along the axis of the main powerhouse. The length of the main powerhouse in the underground powerhouse is $217.5 \mathrm{~m}$, the arch span is $28.3 \mathrm{~m}$, the maximum excavation depth is $68.3 \mathrm{~m}$, the horizontal burial depth is $400-640 \mathrm{~m}$, and the vertical burial depth is 320-500 m. Two faults F1 and F2 and a lamprophyre $\mathrm{L} 1$ are found in the engineering site, as shown in Fig. 5.

The distribution of the ten measured points is shown in Fig. 5, and the measured in situ stress data are shown in Table 1. As the measured in situ stress is obtained in the geodetic coordinate system, it needs to be converted to a model coordinate system, as shown in Table 2. The measured in situ stress in the underground powerhouse has the following distribution characteristics.

(1) The maximum principal stress $\sigma_{1}$ is $14.88-28.96 \mathrm{MPa}$, the intermediate principal stress $\sigma_{2}$ is $8.53-20.37 \mathrm{MPa}$, and the minimum principal stress $\sigma_{3}$ is $3.14-10.88 \mathrm{MPa}$, indicating that the rock mass is in a triaxially unequal pressure state.

(2) The average values of $\sigma_{x} / \sigma_{z}$ and $\sigma_{y} / \sigma_{z}$ are 1.44 and 1.22, respectively, indicating that the measured values of in situ stress show $\sigma_{x}>\sigma_{y}>\sigma_{z}$. However, $\sigma_{y} / \sigma_{z}$ of point 5 is significantly less than average.

(3) The average density $\rho$ and Poisson's ratio $\mu$ of the rock mass are $2600 \mathrm{~kg} / \mathrm{m}^{3}$ and 0.3 , respectively, and the lateral stress coefficient $\lambda=\mu /(1-\mu)$ is 0.4286 . The average values of $\sigma_{x} / \lambda \sigma_{z}$ and $\sigma_{y} / \lambda \sigma_{z}$ are 3.3559 and 2.8433, 


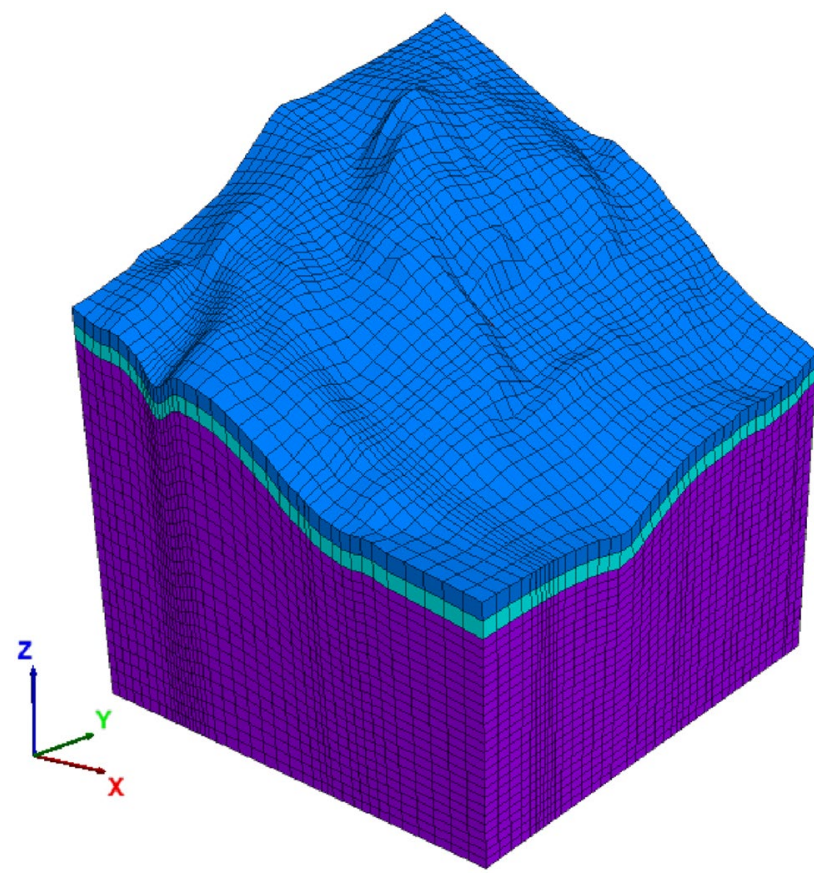

Figure 4. 3D model of the mountain where the Shuangjiangkou hydropower station located.

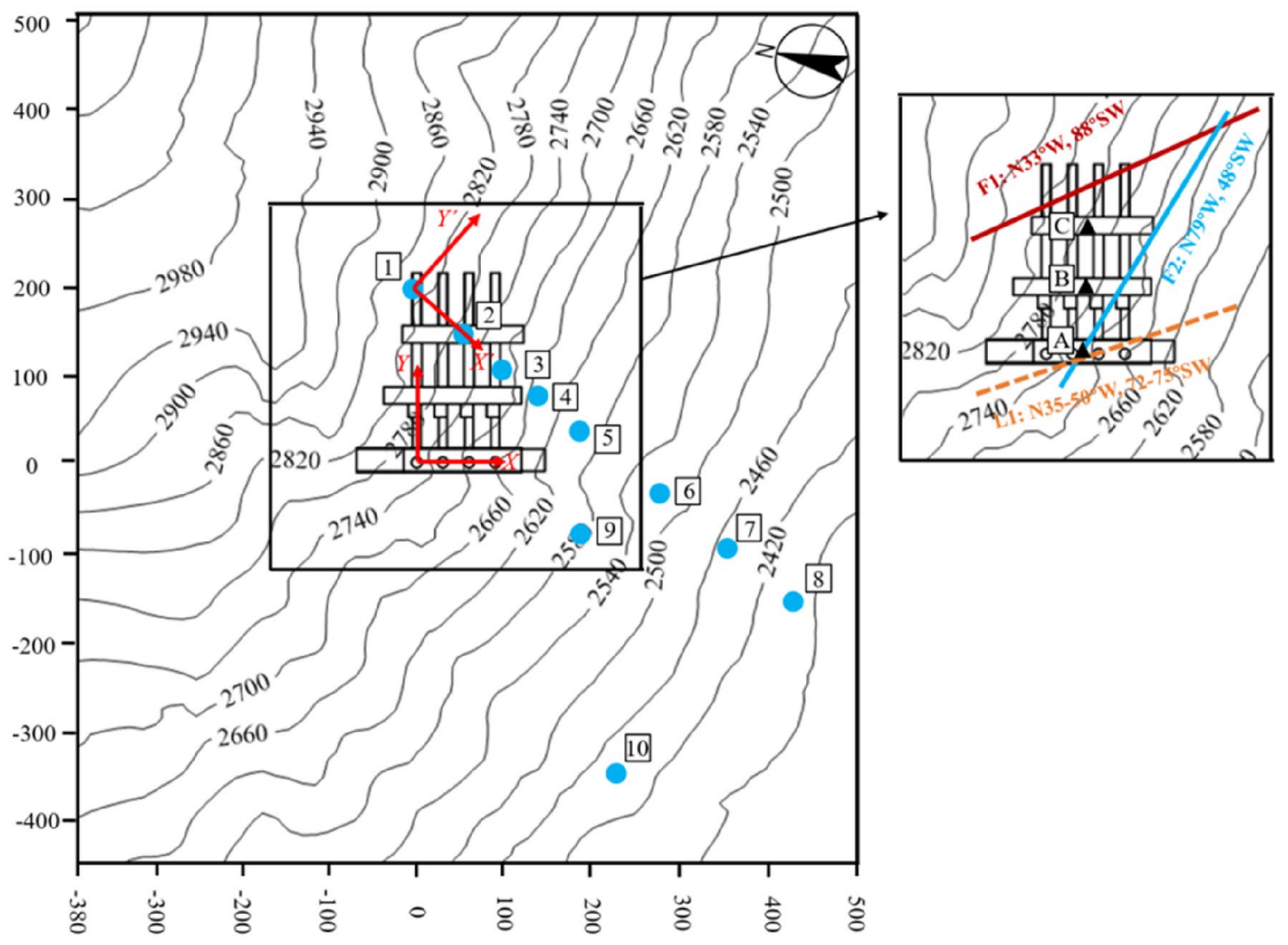

Figure 5. Schematic diagram of the underground powerhouses, faults, and measured points. 


\begin{tabular}{|c|c|c|c|c|c|c|c|c|c|c|c|}
\hline \multirow[b]{2}{*}{ Point } & \multirow[b]{2}{*}{ Altitude (m) } & \multirow[b]{2}{*}{ Depth (m) } & \multicolumn{3}{|l|}{$\sigma_{1}$} & \multicolumn{3}{|l|}{$\sigma_{2}$} & \multicolumn{3}{|l|}{$\sigma_{3}$} \\
\hline & & & \begin{tabular}{|l}
$\begin{array}{l}\text { Magnitude } \\
\text { (MPa) }\end{array}$ \\
\end{tabular} & Direction $\left({ }^{\circ}\right)$ & Dip angle $\left({ }^{\circ}\right)$ & $\begin{array}{l}\text { Magnitude } \\
\text { (MPa) }\end{array}$ & Direction $\left({ }^{\circ}\right)$ & Dip angle $\left({ }^{\circ}\right)$ & $\begin{array}{l}\text { Magnitude } \\
\text { (MPa) }\end{array}$ & Direction $\left(^{\circ}\right)$ & Dip angle $\left(^{\circ}\right)$ \\
\hline 1 & 2268 & 549 & 24.56 & 349.0 & 18.0 & 20.37 & 92.0 & 35 & 10.52 & 237.0 & 49.0 \\
\hline 2 & 2268 & 470 & 28.96 & 325.0 & 27.2 & 18.83 & 72.5 & 30.3 & 10.88 & 201.4 & 47.0 \\
\hline 3 & 2268 & 431 & 16.91 & 357.0 & 19.0 & 10.32 & 92.0 & 14.0 & 8.01 & 216.0 & 66.0 \\
\hline 4 & 2268 & 357 & 27.29 & 310.4 & -3.5 & 18.27 & 36.8 & 45.6 & 8.49 & 223.8 & 44.2 \\
\hline 5 & 2268 & 308 & 37.82 & 331.6 & 46.8 & 16.05 & 54.1 & -7.0 & 8.21 & \begin{tabular}{ll|}
137.7 \\
\end{tabular} & 42.3 \\
\hline 6 & 2268 & 238 & 19.21 & 323.0 & -3.5 & 13.61 & 49.2 & 8.6 & 5.57 & 300.4 & 64.8 \\
\hline 7 & 2268 & 173 & 22.11 & 332.0 & 30.1 & 11.63 & 84.0 & 32.9 & 5.86 & 210.1 & 42.3 \\
\hline 8 & 2268 & 107 & 15.98 & 325.6 & 30.1 & 8.53 & 81.8 & 37.3 & 3.14 & 208.5 & 38.1 \\
\hline 9 & 2405 & 185 & 15.88 & 78.3 & 23.8 & 10.38 & 335.5 & 26.7 & 5.14 & 203.9 & 52.8 \\
\hline 10 & 2272 & 183 & 14.88 & 30.6 & 23.2 & 10.19 & 138.8 & 36.2 & 7.50 & 275.4 & 44.8 \\
\hline
\end{tabular}

Table 1. In situ stress parameters measured. Positive normal stress indicates compression and negative normal stress indicates tension.

\begin{tabular}{|l|l|l|r|r|l|l|}
\hline Point & $\sigma_{x}$ & $\sigma_{y}$ & \multicolumn{1}{|l|}{$\sigma_{z}$} & \multicolumn{1}{|c|}{$\tau_{y z}$} & $\tau_{x z}$ & \multicolumn{1}{c|}{$\tau_{x y}$} \\
\hline 1 & 23.490 & 16.921 & 15.039 & 4.441 & -3.192 & 1.539 \\
\hline 2 & 22.743 & 19.263 & 16.663 & 0.329 & -7.109 & 4.708 \\
\hline 3 & 15.953 & 10.206 & 9.081 & 0.863 & -2.595 & -0.515 \\
\hline 4 & 21.855 & 18.641 & 13.554 & 4.293 & -2.465 & 6.811 \\
\hline 5 & 22.183 & 15.843 & 24.054 & -5.520 & -3.605 & 1.124 \\
\hline 6 & 16.739 & 13.732 & 7.919 & 3.283 & 3.838 & 1.181 \\
\hline 7 & 16.884 & 11.069 & 11.647 & 0.448 & -6.522 & 3.855 \\
\hline 8 & 11.120 & 8.191 & 8.347 & 0.306 & -4.991 & 3.721 \\
\hline 9 & 9.071 & 14.386 & 7.943 & 3.437 & -2.153 & 0.744 \\
\hline 10 & 12.368 & 10.614 & 9.587 & 2.407 & -0.933 & -2.304 \\
\hline
\end{tabular}

Table 2. In situ stress components ( $\mathrm{MPa})$.

respectively, which are greater than 1.0. This indicates that the horizontal stress component in the measured stress is larger than the horizontal stress formed by Poisson's ratio effect of the rock mass gravity. Therefore, there is a horizontal tectonic stress field in this area.

(4) $\sigma_{x} / \sigma_{y}$ is greater than 1.00 , indicating that the horizontal tectonic stress in the $Y$ direction is smaller than that in the $X$ direction.

(5) $\sigma_{z} / \rho g h$ is the ratio of $\sigma_{z}$ at a point to the vertical stress formed by gravity of the overlying rock mass. Except for at the measured point $3, \sigma_{z} / \rho g h$ is $1.08-3.06$, and the average value is 1.97 .

Point 3 and point 5 are relatively near Fault 2 and the lamprophyre, respectively, which may cause undulation of the measured value ${ }^{10}$. Therefore, in the inversion of the initial in situ stress, points 3 and 5 are not used.

\section{Inversion and analysis of stress field}

Approximate stress field. By the analysis of the measured in situ stress in "Project overview and in situ stress measurement analysis", except for measured points 3 and 5, other measured in situ stress points are considered to be representative sample points. In Table 3, the actual lateral stress coefficients $k_{i}$ for the six stress components can be calculated. Based on Eq. (3), the relationship between the present burial depth and $k_{i}$ is shown in Fig. 6. The fitted stress function can be imported into FLAC3D to form an approximate ancient stress field. As shown in Fig. 7, the $Z$ direction range of the ancient model is from the bottom elevation of $1970 \mathrm{~m}$ to the planation plane. The upper six layers in the model are elements for excavation, which are used to simulate the denudation process of the valley. The parameters input to the ancient model in FLAC3D are listed in Table 4. The coordinates of elements containing both rock masses and faults are exported by the FISH language. Then, the parameters of equivalent elements are calculated based on "Equivalent mechanical parameters of faults" and assigned to the model. The equivalent element is calculated using a transversely isotropic elastic constitutive model.

In FLAC3D, each element zone stores six stress components, and each element grid point stores unbalanced forces. If unbalanced forces in the $X, Y, Z$ directions are not applied to model element grid points, stresses in element zones change, and the calculated results of the model greatly deviate from the real results. To optimize 


\begin{tabular}{|l|l|l|l|l|l|l|}
\hline Point & $\boldsymbol{k}_{\mathbf{1}}$ & $\boldsymbol{k}_{\mathbf{2}}$ & $\boldsymbol{k}_{\mathbf{3}}$ & $\boldsymbol{k}_{\mathbf{4}}$ & $\boldsymbol{k}_{\mathbf{5}}$ & $\boldsymbol{k}_{\mathbf{6}}$ \\
\hline 1 & 1.7122 & 1.2334 & 1.0962 & 0.3237 & -0.2327 & 0.1122 \\
\hline 2 & 1.9363 & 1.6401 & 1.4187 & 0.0280 & -0.6053 & 0.4008 \\
\hline 4 & 2.4497 & 2.0895 & 1.5193 & 0.4812 & -0.2763 & 0.7634 \\
\hline 6 & 2.8144 & 2.3088 & 1.3315 & 0.5520 & 0.6453 & 0.1986 \\
\hline 7 & 3.9054 & 2.5603 & 2.6940 & 0.1036 & -1.5086 & 0.8917 \\
\hline 8 & 4.1587 & 3.0633 & 3.1216 & 0.1144 & -1.8665 & 1.3916 \\
\hline 9 & 1.9621 & 3.1117 & 1.7181 & 0.7434 & -0.4657 & 0.1609 \\
\hline 10 & 2.7045 & 2.3209 & 2.0964 & 0.5263 & -0.2040 & -0.5038 \\
\hline
\end{tabular}

Table 3. Lateral stress coefficient $k_{i}$ for six stress components.

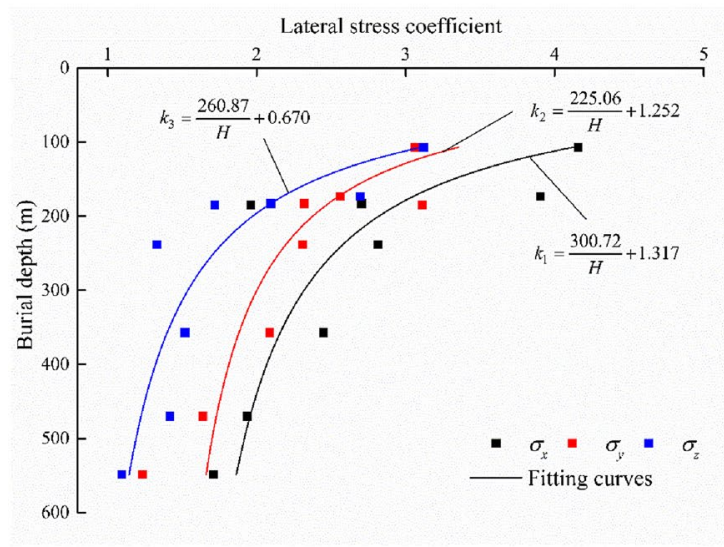

(a) $k_{1}, k_{2}$ and $k_{3}$

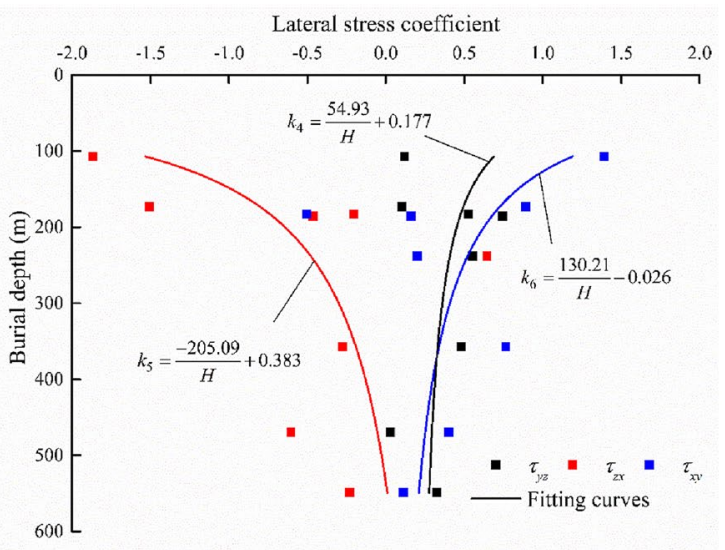

(b) $k_{4}, k_{5}$ and $k_{6}$

Figure 6. Relationship between burial depth and $k_{i}$.

the model in subsequent calculations, based on guidelines of the FLAC3D user manual, the model is performed as follows ${ }^{60}$ to perform ground stress balance.

(1) Based on Eq. (3), ancient stress field can be calculated and imported to the ancient model in FLAC3D, then the parameters of the rock mass are input to the model.

(2) The boundary normal velocities of the ancient model periphery and bottom surfaces are fixed to zero.

(3) Calculate the model for one step, that is, run the step 1 command to solve the model, and then record the unbalanced forces on element grid points.

(4) Apply forces opposite to unbalanced forces recorded in (2) to each element grid point in the ancient model.

(5) Repeat (3) and (4) several times to make the stress components close enough to the stress components in the ancient model.

After the above process, the balance calculation of the approximate ancient field is completed. Excavating ancient strata layer by layer can obtain the present in situ stress field. Six stress components and lateral stress coefficients at the measured points can be obtained. However, these lateral stress coefficients are obtained by approximating the ancient stress field, so there may be some unacceptable errors, and further optimized regression factors need to be determined.

Optimized stress field. By using a GAN to inversely optimize the present stress field, it is necessary to construct adequate real samples for training. Since the initial in situ stress inversion of this project is to provide accurate ground stress for the underground cavern excavation, the measured points in and around the underground cavern need to be selected as samples. In addition, boundary effects occur in numerical excavation simulations, so measured points near the boundary of the numerical model need to be selected as samples. Therefore, the measured point in Table 3 can be as samples to GAN training. Based on a large number of trial calculations ${ }^{25}$, the floating range of regression factors in Eq. (3) is determined. The value range of each regression factor $a_{i}$ or $b_{i}$ is between 0.5 and 1.5 times of itself. Twelve regression factors are taken as factors of the uniform design test, and different values of regression factors are regarded as different levels. Based on the principle of uniform design, there are 13 levels for regression factors. Then, levels $1-13$ correspond to regression factors $0.52,0.60,0.68,0.76$, $0.84,0.92,1.00,1.08,1.16,1.24,1.32,1.40$, and 1.48 times, respectively, so the $U_{13}$ uniform table is selected ${ }^{56}$, 


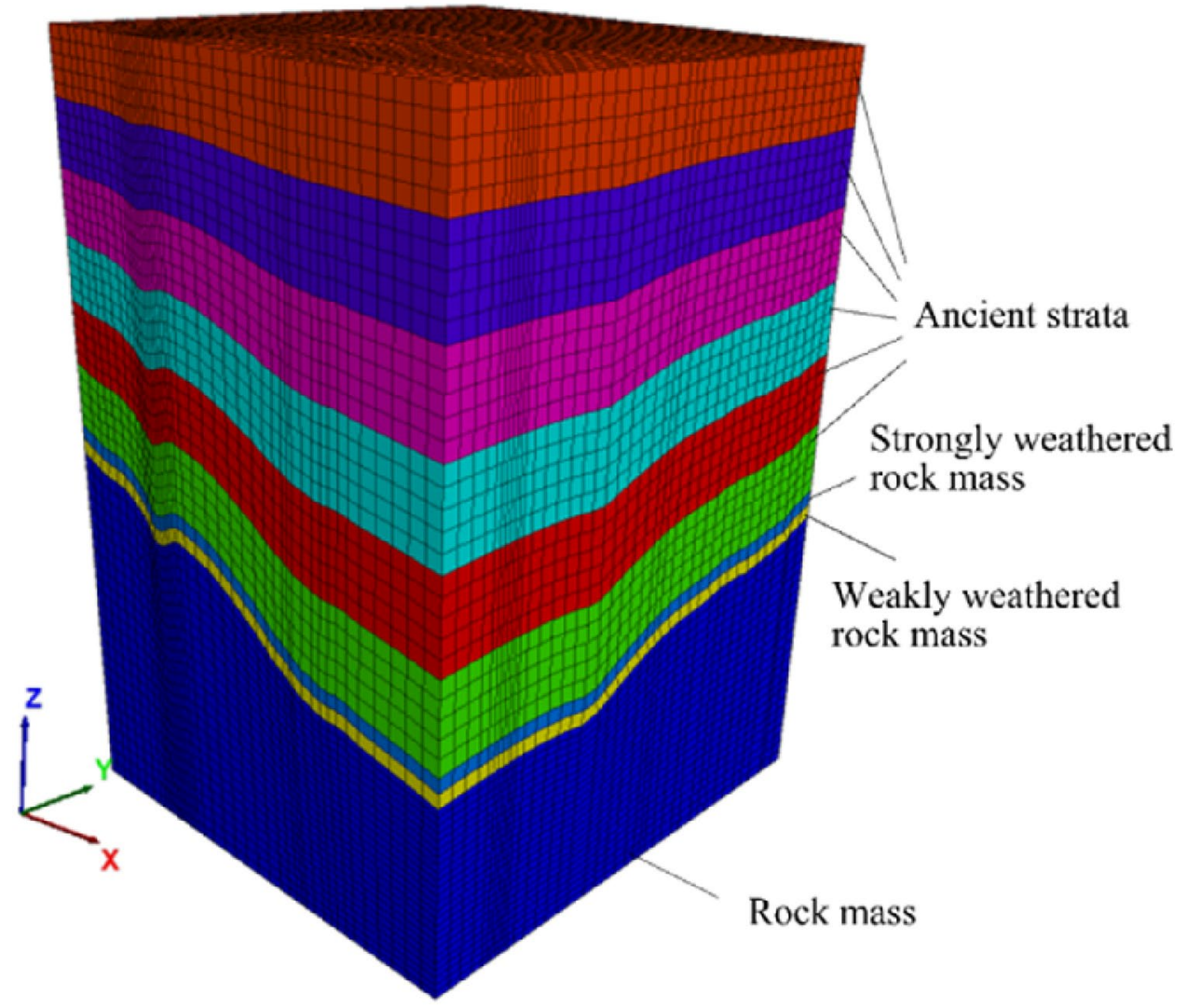

Figure 7. The ancient model.

\begin{tabular}{|l|l|l|l|l|l|}
\hline Type of rock mass & $\begin{array}{l}\text { Bulk density } \boldsymbol{\gamma}(\mathbf{k N} / \\
\left.\mathbf{m}^{3}\right)\end{array}$ & $\begin{array}{l}\text { Deformation modulus } \\
\boldsymbol{E}(\mathrm{GPa})\end{array}$ & Poisson ratio $\boldsymbol{\mu}$ & $\begin{array}{l}\text { Internal friction } \\
\text { coefficient } \boldsymbol{f}\end{array}$ & Cohesion $\boldsymbol{c}(\mathbf{M P a})$ \\
\hline Unweathered & 26.0 & 12.5 & 0.30 & 1.25 & 1.55 \\
\hline Weakly weathered & 25.5 & 7.0 & 0.32 & 0.95 & 0.90 \\
\hline Strongly weathered & 23.5 & 3.0 & 0.35 & 0.70 & 0.40 \\
\hline Weak structural plane & 18.0 & 0.3 & 0.38 & 0.40 & 0.03 \\
\hline
\end{tabular}

Table 4. The parameters for numerical simulations.

as shown in Table 5. Regression factors of each test can be taken into Eqs. (1) and (3) to calculate the stress components of each element, which can be imported into FLAC3D for calculation. In each test, the calculated stress components and lateral stress coefficients of the measured points can be obtained. There are eight effective measured points, so eight training samples can be created in each test, for a total of $13 \times 8=104$ samples.

After training with real data samples, input $x$ and $y$ coordinates, present burial depth and lateral stress coefficient of the measured points in the present stress field of measured points, the regression factors of the ancient stress field can be obtained. Then, the optimized ancient stress field can be obtained by Eq. (3). Figure 8 shows the relationship between the loss function of generator and discriminator in GAN and iterations. The generator $G$ and the discriminator network $D$ are continuously confronted, so that the loss function of the two network reduces to a minimum, indicating that the output sample data from generator is stable. After GAN training, the regression factors of the optimized ancient stress field can be predicted, so the optimized ancient stress field can be obtained by Eq. (3). After excavating the optimized ancient stress field, the present stress field can be obtained. The regression factors and calculated stress values of the measured points are listed in Tables 6 and 7 . The relative error $\Delta$ of the measured points can be calculated:

$$
\Delta=\frac{\left\|\hat{\sigma}_{i}-\sigma_{i}\right\|_{2}}{\left\|\sigma_{i}\right\|_{2}} \times 100 \%
$$

where $\hat{\sigma}_{i}$ is the calculated stress component and $\sigma_{i}$ is the measured stress component. $\|\cdots\|_{2}$ is the 2 -Norm. 


\begin{tabular}{|l|l|l|l|l|l|l|l|l|l|l|l|l|}
\hline \multirow{2}{*}{ Test no. } & \multicolumn{10}{|l|}{ Levels of different factors } \\
\cline { 2 - 13 } & $\boldsymbol{a}_{\mathbf{1}}$ & $\boldsymbol{b}_{\mathbf{1}}$ & $\boldsymbol{a}_{\mathbf{2}}$ & $\boldsymbol{b}_{\mathbf{2}}$ & $\boldsymbol{a}_{\mathbf{3}}$ & $\boldsymbol{b}_{\mathbf{3}}$ & $\boldsymbol{a}_{\mathbf{4}}$ & $\boldsymbol{b}_{\mathbf{4}}$ & $\boldsymbol{a}_{\mathbf{5}}$ & $\boldsymbol{b}_{\mathbf{5}}$ & $\boldsymbol{a}_{\mathbf{6}}$ & $\boldsymbol{b}_{\mathbf{6}}$ \\
\hline 1 & 156.37 & 0.790 & 153.04 & 0.952 & 219.13 & 0.616 & 54.93 & 0.191 & -237.90 & 0.475 & 171.88 & -0.036 \\
\hline 2 & 180.43 & 1.001 & 207.06 & 1.352 & 323.48 & 0.938 & 28.56 & 0.120 & -172.28 & 0.383 & 151.04 & -0.034 \\
\hline 3 & 204.49 & 1.212 & 261.07 & 1.753 & 156.52 & 0.563 & 59.32 & 0.234 & -106.65 & 0.291 & 130.21 & -0.032 \\
\hline 4 & 228.55 & 1.422 & 315.08 & 0.851 & 260.87 & 0.884 & 32.96 & 0.163 & -254.31 & 0.199 & 109.38 & -0.030 \\
\hline 5 & 252.60 & 1.633 & 135.04 & 1.252 & 365.22 & 0.509 & 63.72 & 0.092 & -188.68 & 0.506 & 88.54 & -0.028 \\
\hline 6 & 276.66 & 1.844 & 189.05 & 1.653 & 198.26 & 0.831 & 37.35 & 0.205 & -123.05 & 0.414 & 67.71 & -0.026 \\
\hline 7 & 300.72 & 0.685 & 243.06 & 0.751 & 302.61 & 0.456 & 68.11 & 0.135 & -270.72 & 0.322 & 182.29 & -0.024 \\
\hline 8 & 324.78 & 0.896 & 297.08 & 1.152 & 135.65 & 0.777 & 41.75 & 0.248 & -205.09 & 0.230 & 161.46 & -0.022 \\
\hline 9 & 348.84 & 1.106 & 117.03 & 1.552 & 240.00 & 0.402 & 72.51 & 0.177 & -139.46 & 0.536 & 140.63 & -0.020 \\
\hline 10 & 372.89 & 1.317 & 171.05 & 0.651 & 344.35 & 0.724 & 46.14 & 0.106 & -287.13 & 0.444 & 119.79 & -0.018 \\
\hline 11 & 396.95 & 1.528 & 225.06 & 1.052 & 177.39 & 0.348 & 76.90 & 0.219 & -221.50 & 0.352 & 98.96 & -0.016 \\
\hline 12 & 421.01 & 1.738 & 279.07 & 1.452 & 281.74 & 0.670 & 50.54 & 0.149 & -155.87 & 0.260 & 78.13 & -0.014 \\
\hline 13 & 445.07 & 1.949 & 333.09 & 1.853 & 386.09 & 0.992 & 81.30 & 0.262 & -303.53 & 0.567 & 192.71 & -0.038 \\
\hline
\end{tabular}

Table 5. $\mathrm{U}_{13}$ uniform table of levels combination of different factors in each test.

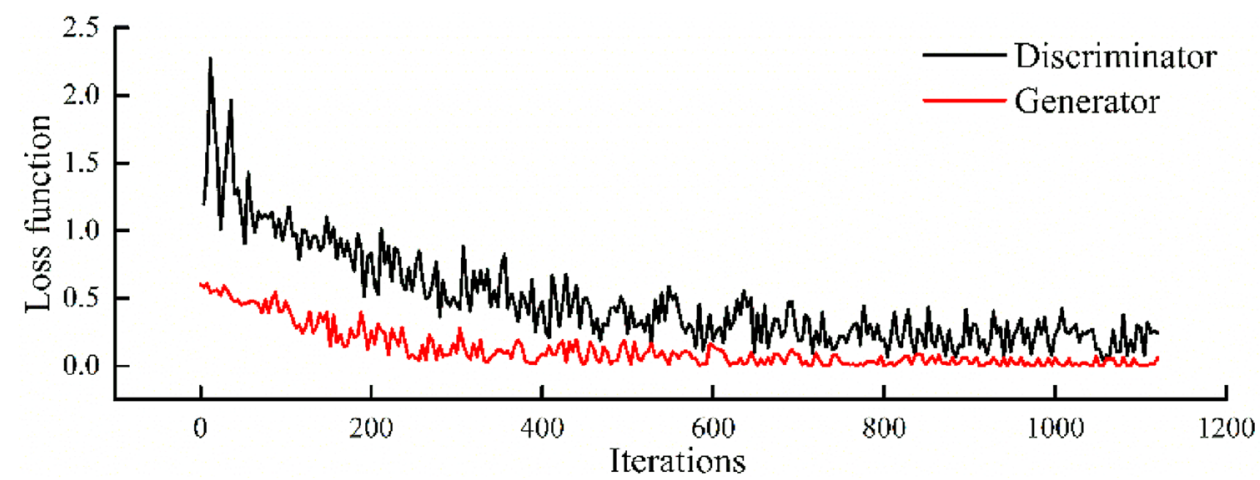

Figure 8. The loss function of GAN.

\begin{tabular}{|l|c|c|c|l|l|l|}
\hline \multicolumn{6}{|l|}{ Regression factor of stress components } \\
\cline { 2 - 7 } & $\sigma_{x}$ & $\sigma_{y}$ & $\sigma_{z}$ & $\tau_{y z}$ & $\tau_{x z}$ & $\tau_{x y}$ \\
\hline GAN & 174.58 & 165.36 & 395.52 & 45.63 & -215.36 & 139.10 \\
\hline$a_{i}$ & 1.236 & 0.801 & 0.526 & 0.365 & 0.326 & 0.003 \\
\hline$b_{i}$ & BP neural network & & & \\
\hline$a_{i}$ & 185.30 & 160.69 & 382.25 & 48.65 & -201.36 & 139.45 \\
\hline$b_{i}$ & 0.999 & 0.833 & 0.610 & 0.224 & 0.220 & -0.016 \\
\hline
\end{tabular}

Table 6. Regression factors in ancient stress field obtained by GAN and BP neutral network.

For comparison, regression factor of stress components obtained by GAN and BP neural network are also listed in Tables 6 and 7. For these method, the relative errors of $\sigma_{x}, \sigma_{y}$ and $\sigma_{z}$ are less than 15\%, which is more optimized than $\tau_{y z}, \tau_{x z}$ and $\tau_{x y}$. According to statistical data, the error of in situ stress measurement results can reach $25-30 \%{ }^{61}$. The maximum relative error of the measured points with GAN is $17.46 \%$, so the distribution law of the in situ stress field is reasonable. For BP method, the maximum relative error for Point 8 reaches $28.4 \%$, so the average relative error of GAN is much smaller than that of BP neural network, especially for the inversion of $\tau_{y z}, \tau_{x z}$ and $\tau_{x y}$.

Analysis of present in situ stress field based on GAN inversion method. Based on the calculated present stress field, the contour maps of $y^{\prime}=0$ in Fig. 3 including some measured points are shown in Fig. 9. The topography has a significant influence on the in situ stress distribution in the engineering area, while the lithology has a small influence on the stress field. From the top to the bottom of the Earth's surface, $\sigma_{x}, \sigma_{y}$ and 


\begin{tabular}{|c|c|c|c|c|c|c|c|}
\hline Point & $\sigma_{x}(\mathrm{MPa})$ & $\sigma_{y}(\mathrm{MPa})$ & $\sigma_{z}(\mathrm{MPa})$ & $\tau_{y z}(\mathrm{MPa})$ & $\tau_{x z}(\mathrm{MPa})$ & $\tau_{x y}(\mathrm{MPa})$ & Relative error (\%) \\
\hline \multicolumn{8}{|l|}{1} \\
\hline Measured & 23.490 & 16.921 & 15.039 & 4.441 & -3.192 & 1.539 & \\
\hline GAN & 25.153 & 18.653 & 16.053 & 5.012 & -3.036 & 1.754 & 8.10 \\
\hline $\mathrm{BP}$ & 25.632 & 18.312 & 15.851 & 5.265 & -2.880 & 2.215 & 8.76 \\
\hline \multicolumn{8}{|l|}{2} \\
\hline Measured & 22.743 & 19.263 & 16.663 & 0.329 & -7.109 & 4.708 & \\
\hline GAN & 23.965 & 17.523 & 15.056 & 1.253 & -6.326 & 3.215 & 9.34 \\
\hline $\mathrm{BP}$ & 24.262 & 17.286 & 15.116 & 1.189 & -5.955 & 3.240 & 10.18 \\
\hline \multicolumn{8}{|l|}{4} \\
\hline Measured & 21.855 & 18.641 & 13.554 & 4.293 & -2.465 & 6.811 & \\
\hline GAN & 22.365 & 15.213 & 14.245 & 5.213 & -2.523 & 5.036 & 12.36 \\
\hline $\mathrm{BP}$ & 21.689 & 15.623 & 13.901 & 5.132 & -2.250 & 5.189 & 10.82 \\
\hline \multicolumn{8}{|l|}{6} \\
\hline Measured & 16.739 & 13.732 & 7.919 & 3.283 & 3.838 & 1.181 & \\
\hline GAN & 17.523 & 13.201 & 10.653 & 4.456 & 1.253 & 1.956 & 17.46 \\
\hline $\mathrm{BP}$ & 17.813 & 13.333 & 11.442 & 4.779 & -0.842 & 2.004 & 25.58 \\
\hline \multicolumn{8}{|l|}{7} \\
\hline Measured & 16.884 & 11.069 & 11.647 & 0.448 & -6.522 & 3.855 & \\
\hline GAN & 15.523 & 12.236 & 11.985 & 0.523 & -4.985 & 3.562 & 9.81 \\
\hline $\mathrm{BP}$ & 15.621 & 12.172 & 10.605 & 0.884 & -5.853 & 2.913 & 9.50 \\
\hline \multicolumn{8}{|l|}{8} \\
\hline Measured & 11.120 & 8.191 & 8.347 & 0.306 & -4.991 & 3.721 & \\
\hline GAN & 11.735 & 10.32 & 8.563 & 0.521 & -3.652 & 3.263 & 15.30 \\
\hline $\mathrm{BP}$ & 11.735 & 11.680 & 9.762 & 1.723 & -2.315 & 3.073 & 28.40 \\
\hline \multicolumn{8}{|l|}{9} \\
\hline Measured & 9.071 & 14.386 & 7.943 & 3.437 & -2.153 & 0.744 & \\
\hline GAN & 8.896 & 16.236 & 7.523 & 3.236 & -2.475 & 0.856 & 10.12 \\
\hline $\mathrm{BP}$ & 9.374 & 15.816 & 8.154 & 4.263 & -3.002 & 0.594 & 9.88 \\
\hline \multicolumn{8}{|l|}{10} \\
\hline Measured & 12.368 & 10.614 & 9.587 & 2.407 & -0.933 & -2.304 & \\
\hline GAN & 12.956 & 10.985 & 10.036 & 2.563 & -0.902 & -1.365 & 6.56 \\
\hline $\mathrm{BP}$ & 13.751 & 11.448 & 10.308 & 2.154 & -1.368 & 0.216 & 16.23 \\
\hline
\end{tabular}

Table 7. Stress component values of each measured point based on GAN and BP neutral network.

$\sigma_{z}$ increase with increasing depth. Due to the weak mechanical parameters at faults and lamprophyre, there are stress release effects in these areas. The stress components of the faults and lamprophyre all drop sharply, and the stress components of nearby rock masses also decrease. Figure 10 shows the principal stress contour map of Unit 1 in the main powerhouse, indicating that.

(1) The principal stress changes with the topography, and the surface unloading area has a small deformation modulus due to the relaxation of the rock mass structure, so there is a stress relaxation.

(2) When the horizontal and vertical burial depths increase, the values of $\sigma_{1}$ and $\sigma_{3}$ gradually increase, and the contour lines are roughly parallel to the hillside.

(3) With the increase in the depth of the caves, the stress value of the cave surrounding rock also increases, and the stress of the tailwater surge chamber is higher than that of the main powerhouse. The excavation and unloading stresses at the lower part of each cave are higher than those at the top arch, indicating that the excavation unloading effect of the lower part of the cave is more pronounced.

(4) The stress field presents distribution characteristics of $\sigma_{x}>\sigma_{y}>\sigma_{z}$, which is advantageous to excavation of the cave sidewalls, but the stability of the end wall is unfavorable.

The lateral stress coefficients $k_{1}-k_{6}$ along the perpendicular line through Points A, B and C in Fig. 5 of the center of the three caverns are shown in Fig. 11. The calculated values of the lateral stress coefficients are close to the measured points but disperse from the main curve when the location is at the fault or lamprophyre. The lateral stress coefficients decrease with increasing burial depth and gradually tend to a constant value. The fitting curve shows the relationship between burial depth and lateral pressure coefficient Points A, B and C. The relationship is in accordance with Eq. (3), which can be directly imported into the numerical model with a cavern group for excavation simulation. 


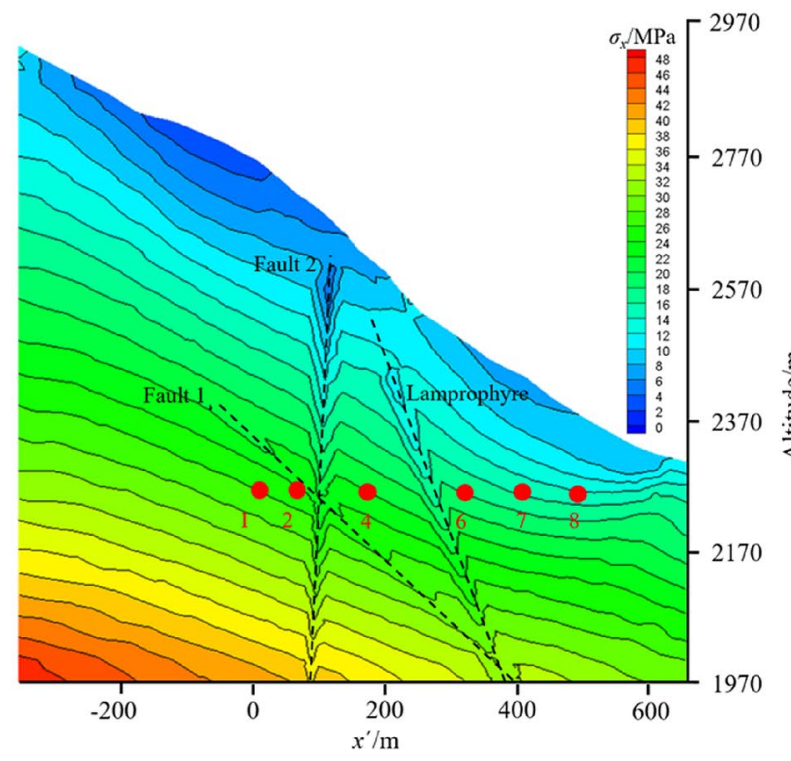

(a) Stress contour of $\sigma_{x}$

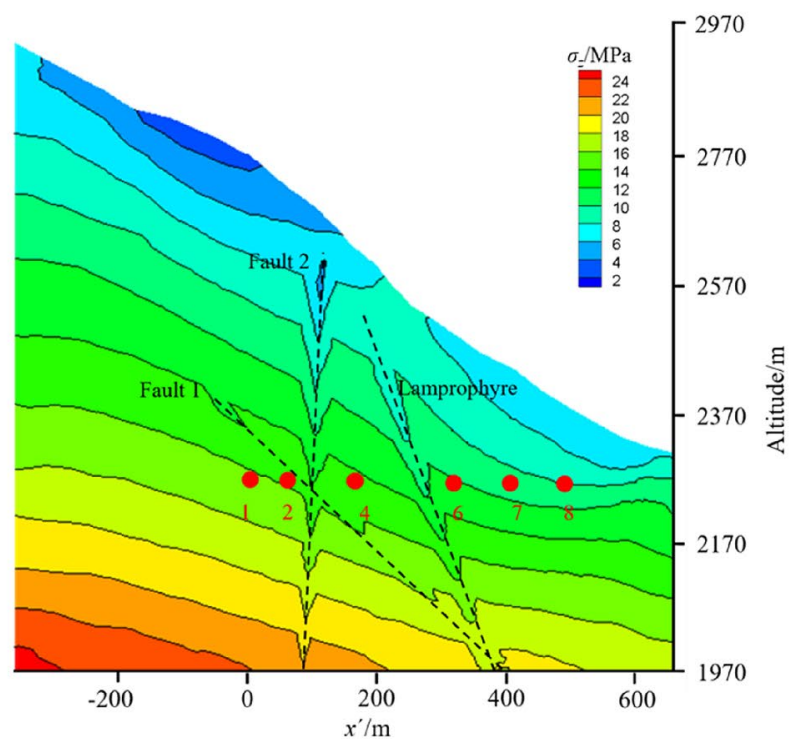

(c) Stress contour of $\sigma_{z}$

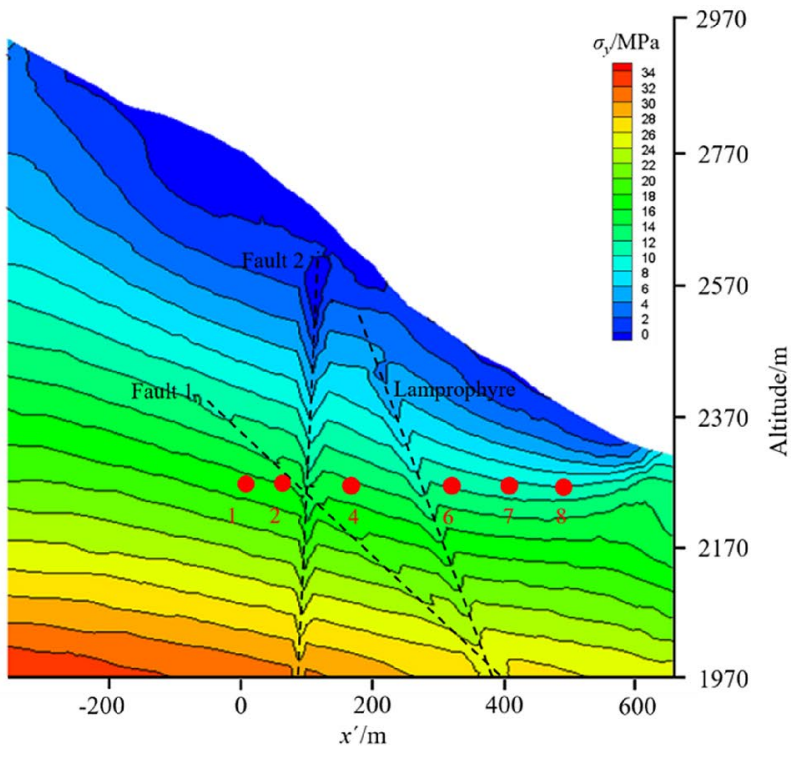

(b) Stress contour of $\sigma_{y}$

Figure 9. Stress contour of $\sigma_{x}, \sigma_{y}, \sigma_{z}$ at $y^{\prime}=0$. 


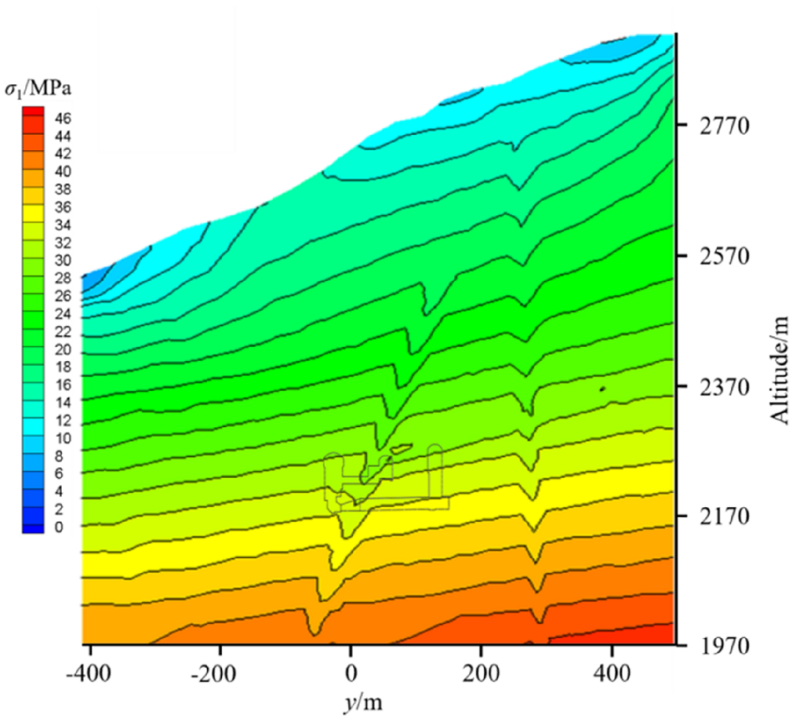

(a) Maximum principal stress $\sigma_{1}$

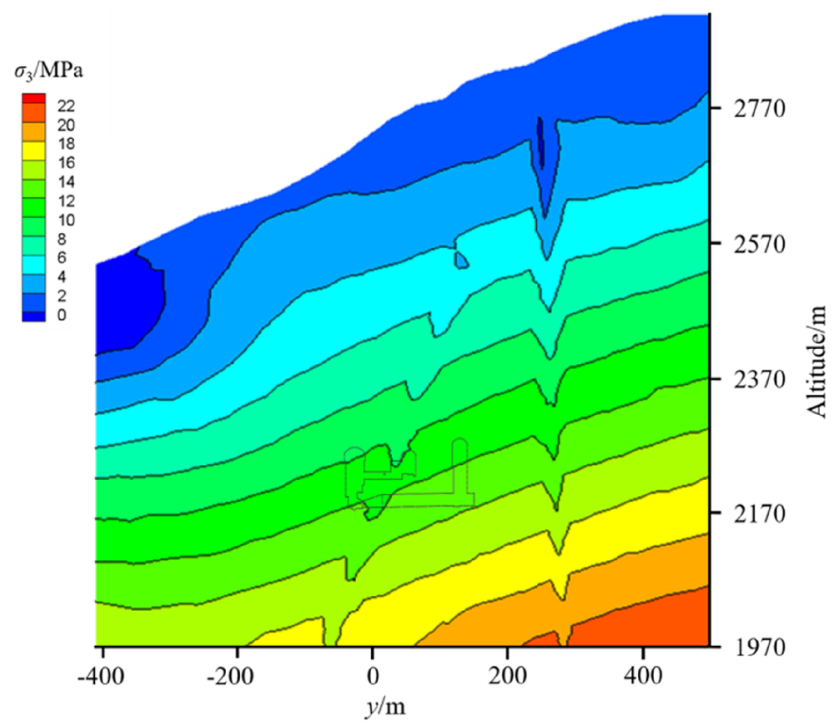

(b) Minimum principal stress $\sigma_{3}$

Figure 10. Principal stress contour at $x=0$.

\section{Conclusion}

The in situ stress field of the Shuangjiangkou Hydropower Station is mainly composed of tectonic stress and gravity stress, and its distribution is affected by the tectonic stress, geological structure and topography. In this paper, the ancient stratum excavation method combined with the lateral stress coefficient and GAN is utilized to invert the in situ stress field. By comparing with measured points, the feasibility of this method to invert the in situ stress field is verified.

(1) The in situ stress value is positively correlated with the burial depth and the lateral stress coefficient. For deep buried engineering, the lateral stress coefficient is inversely proportional to the burial depth and tends to a constant value, rather than following the commonly used linear relationship.

(2) Instead of inverting the stress at measured points with the artificial intelligence method, the regression factor of the lateral stress coefficient in ancient times is determined by GAN. Then, the in situ stress field is obtained by strata excavation to simulate the geological effects of surface erosion and weathering to inverse the present in situ stress field.

(3) Elements containing both rock masses and faults are regarded as equivalent elements of transverse isotropy, thereby reducing the difficulty of numerical model modeling and calculation time.

(4) The inverted in situ stress components are close to the measured values, so the obtained in situ stress field is reasonable; thus, the inverted in situ stress field can reflect the distribution law of the actual in situ stress field and can provide reasonable guidance for the excavation simulation and stability analysis of underground caverns.

(5) Based on the in situ stress field obtained by the inversion analysis, the equation of the lateral stress coefficient and the burial depth can be obtained. In subsequent cavern excavation simulations, a refined model with a cavern group can be established, and the reversed geostress equation can be directly imported into the model.

In summary, this paper proposes a new inversion method of the in situ stress field, which can provide a more optimized in situ stress field for deep-buried engineering. 


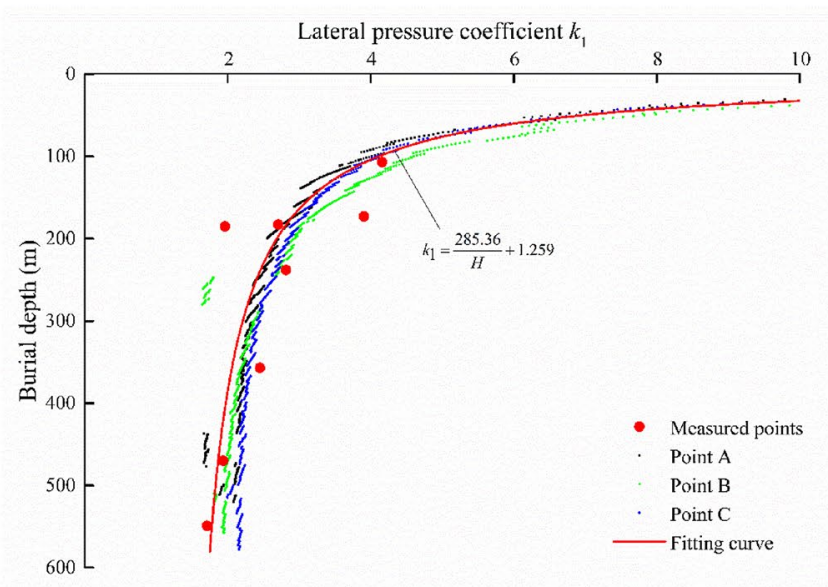

(a) Curve of $k_{1}$ and burial depth

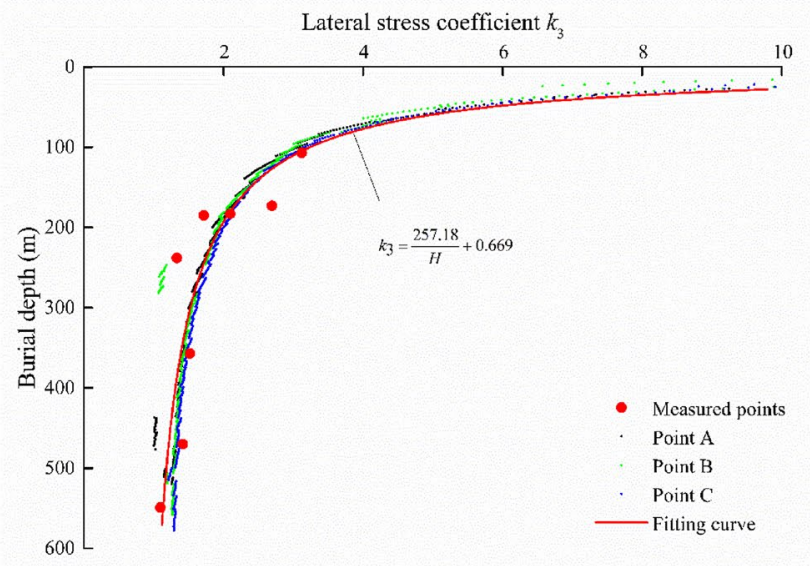

(c) Curve of $k_{3}$ and burial depth

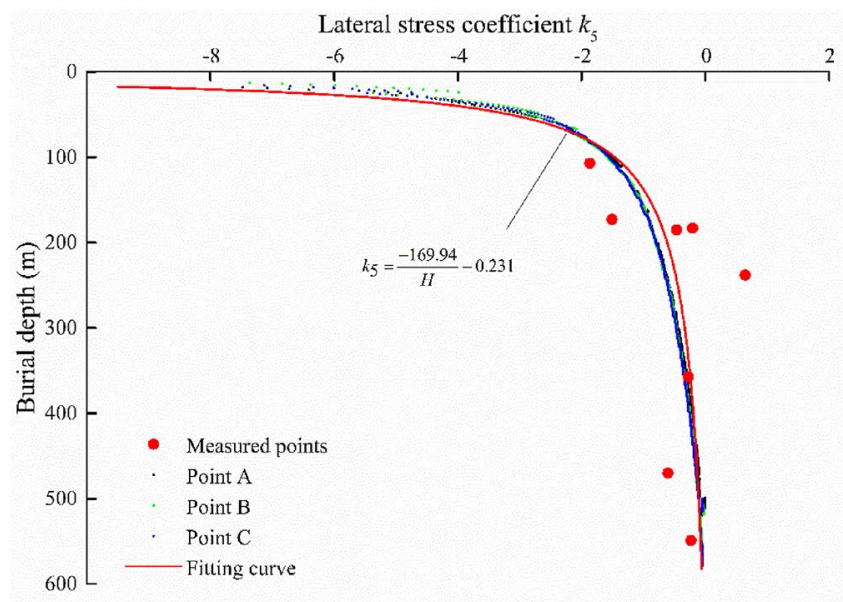

(e) Curve of $k_{5}$ and burial depth

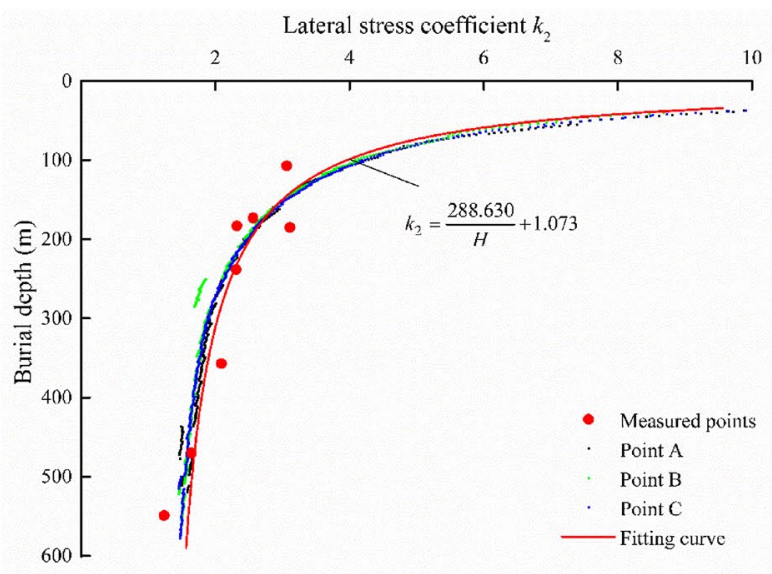

(b) Curve of $k_{2}$ and burial depth

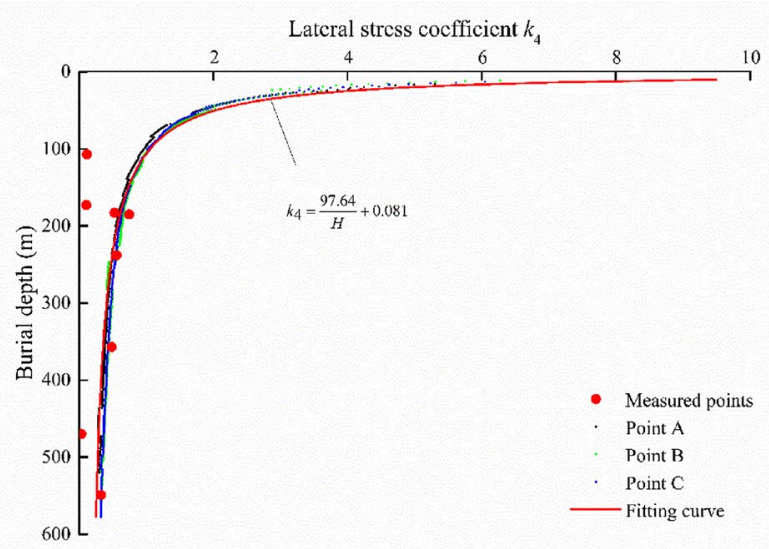

(d) Curve of $k_{4}$ and burial depth

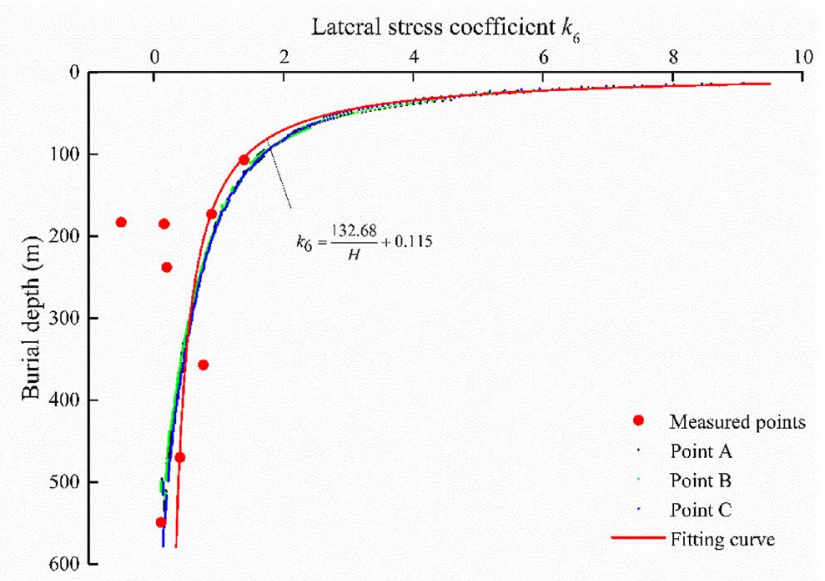

(f) Curve of $k_{6}$ and burial depth

Figure 11. Relationship between $k$ and burial depth. 
Received: 2 July 2021; Accepted: 27 October 2021

Published online: 08 November 2021

\section{References}

1. Gong, M., Qi, S. \& Liu, J. Engineering geological problems related to high geo-stresses at the Jinping I Hydropower Station, Southwest China. B. Eng. Geol. Environ. 69, 373-380 (2010).

2. Xie, H. Q., He, J. D. \& Xiao, M. L. Regression analysis of 3D initial geostress in region of underground powerhouse for large hydropower station. Rock Soil Mech. 30, 2471-2476 (2009) (in Chinese).

3. González de Vallejo, L. I. \& Hijazo, T. A new method of estimating the ratio between in situ rock stresses and tectonics based on empirical and probabilistic analyses. Eng. Geol. 101, 185-194 (2008).

4. Engelder, T. Stress. Regimes in the Lithosphere (Princeton University Press, 1993).

5. Zhang, S. R., Hu, A. K. \& Wang, C. Three-dimensional inversion analysis of an in situ stress field based on a two-stage optimization algorithm. J. Zhejiang Univ. Sci. A 17, 782-802 (2016).

6. Richard, J. L., Tobore, O. O., Luis, A., Carlos, L. \& Deepak, C. Srivastava: Favoured states of palaeostress in the Earth's crust: Evidence from fault-slip data. J. Struct. Geol. 28, 1051-1066 (2006).

7. White, A. J., Traugott, M. O. \& Swarbrick, R. E. The use of leak-off tests as means of predicting minimum in-situ stress. Petrol. Geosci. 8, 189-193 (2002).

8. Liu, B., Zhu, Y. G., Liu, Q. S. \& Liu, X. W. A novel in situ stress monitoring technique for fracture rock mass and its application in deep coal mines. Appl. Sci. 9, 3742 (2019).

9. Sjöberg, J. \& Klasson, H. Stress measurements in deep boreholes using the Borre (SSPB) probe. Int. Rock Mech. Min. 40, 1205-1223 (2003).

10. Haimson, B. C. \& Cornet, F. H. ISRM suggested methods for rock stress estimation-Part 3: Hydraulic fracturing (HF) and/or hydraulic testing of pre-existing fractures (HTPF). Int. Rock Mech. Min. 40, 1011-1020 (2003).

11. Ge, X. \& Hou, M. Principle of in-situ 3D rock stress measurement with borehole wall stress relief method and its preliminary applications to determination of in-situ rock stress orientation and magnitude in Jinping hydropower station. Sci. China Technol. Sci. 55, 939-949 (2012) (in Chinese).

12. Wang, B. L. \& Ma, Q. C. Boundary element analysis methods for ground stress field of rock masses. Comput. Geotech. 2, 261-274 (1986).

13. Zhang, L. H. Pre-processing and post-processing method for geostress simulation using seismic interpretation results. Mining Sci. Technol. (China). 19, 369-372 (2009) (in Chinese).

14. Saati, V. \& Mortazavi, A. Numerical modelling of in situ stress calculation using borehole slotter test. Tun. Undergr. Sp. Tech. 26, 172-178 (2011).

15. McKinnon, S. D. Analysis of stress measurements using a numerical model methodology. Int. Rock Mech. Min. 38, 699-709 (2001).

16. Qin, Z. C., Liu, C. L., Zhao, Z. Y. \& Li, Q. H. Back analysis of initial ground stress by 3D-FSM considering influence of terrain and tectonic stress. Rock Soil Mech. 29, 1848-1852 (2008) (in Chinese).

17. Zhang, S. K., Yuan, Y., Fang, H. Y. \& Wang, F. M. An application of soft computing for the earth stress analysis in hydropower engineering. Soft Comput. 24, 4739-4749 (2020).

18. Guo, M. W., Li, C. G., Wang, S. L. \& Luan, G. B. Study on inverse analysis of 3-D initial geostress field with optimized displacement boundaries. Rock Soil Mech. 29, 1269-1274 (2008) (in Chinese).

19. Zhang, C. Q., Feng, X. T. \& Zhou, H. Estimation of in situ stress along deep tunnels buried in complex geological conditions. Int. Rock Mech. Min. 52, 139-162 (2012)

20. Meng, W. \& He, C. Back Analysis of the Initial geo-stress field of rock masses in high geo-temperature and high geo-stress. Energies 13, 363 (2020)

21. Xu, D. P. et al. Estimation of the three-dimensional in situ stress field around a large deep underground cavern group near a valley. J. Rock Mech. Geotech. https://doi.org/10.1016/j.jrmge.2020.11.007 (2021).

22. Fu, C. H., Wang, W. M. \& Chen, S. H. Back analysis study on initial geostress field of dam site for Xiluodu hydropower project. Chin. J. Rock Mech. Eng. 25, 2305-2312 (2006) (in Chinese).

23. Zhang, Y. H., Wei, Q., Sheng, Q., Leng, X. L. \& Jing, F. Three dimensional back analysis of geostress field in underground powerhouse zone of Dagangshan hydropower station. Rock Soil Mech. 32, 1523-1530 (2011) (in Chinese).

24. Yuan, F. B., Liu, J., Li, P. J., Qiao, L. P. \& Li, P. Back analysis and multiple-factor influencing mechanism of high in-situ stress field for river valley region of Laxiwa hydropower engineering. Rock Soil Mech. 28, 836-842 (2007) (in Chinese).

25. Li, X. P. et al. Inversion method of initial in situ stress field based on BP neural network and applying loads to unit body. Adv. Civ. Eng. 8840940, 15 pages. https://doi.org/10.1155/2020/8840940 (2020)

26. Education Committee of Chinese Society of Rock Mechanics and Engineering. New Developments in Rock Mechanics (Northeast Institute of Technology Press, 1989).

27. Wang, Q. W., Ju, N. P., Du, L. L., Huang, J. \& Jiang, J. Y. Inverse analysis of geostress field in Bayu deep-buried tunnel on LhasaLinzhi railway. Railw. Eng. 10, 59-62 (2016) (in Chinese).

28. Jia, L. Y. The FEM of 3-dimensional back-analysis of displacements. Rock Soil Mech. 17, 1-7 (1996) (in Chinese).

29. Sakurai, S. \& Takeuchi, K. Back analysis of measured displacements of tunnels. Rock Mech. Rock Eng. 16, 173-180 (1983).

30. Kartam, N., Flood, I. \& Garrett, J. H. Artificial Neural Networks for Civil Engineers: Fundamentals and Applications (American Society of Civil Engineers, 1997).

31. Zhang, L. Q., Yue, Z. Q., Yang, Z. F., Qi, J. X. \& Liu, F. C. A displacement-based back-analysis method for rock mass modulus and horizontal in situ stress in tunneling-Illustrated with a case study. Tun. Undergr. Sp. Tech. 21, 636-649 (2006).

32. Zhao, C., Xiao, M. \& Chen, J. T. Inversion analysis method for in-situ stress field under complex geological conditions. J. Huazhong Univ. Sci. Technol. (Nat. Sci. Edn.). 45, 87-92 (2017).

33. Chen, S. J., Xiao, M., Chen, J. T. \& Ren, J. Q. Disturbance law of fault to in-situ stress field directions and its inversion analysis method. Chin. J. Rock Mech. Eng. 39, 1434-1444 (2020).

34. Li, Y. S., Yin, J. M., Chen, J. P. \& Xu, J. Analysis of 3D in-situ stress field and query system's development based on visual BP neural network. Procedia Earth Planet. Sci. 5, 64-69 (2012).

35. Moayedi, H., Mosallanezhad, M., Rashid, A. S. A., Jusoh, W. A. W. \& Muazu, M. A. A systematic review and meta-analysis of artificial neural network application in geotechnical engineering: Theory and applications. Neural Computer Appl. 32, 495-518 (2020).

36. Cui, K. \& Jing, X. Research on prediction model of geotechnical parameters based on BP neural network. Neural Computer Appl. 31, 8205-8215 (2019).

37. Li, G. et al. In-version method of in-situ stress and rock damage characteristics in dam site using neural network and numerical simulation-A case study. IEEE Access. 8, 46701-46712 (2020).

38. Manouchehrian, A., Sharifzadeh, M. \& Moghadam, R. H. Application of artificial neural networks and multivariate statistics to estimate UCS using textural characteristics. Int. J. Min. Sci. Technol. 22, 229-236 (2012).

39. Monjezi, M., Hesami, S. M. \& Khandelwal, M. Superiority of neural networks for pillar stress prediction in bord and pillar method. Arab. J. Geosci. 4, 845-853 (2011). 
40. Wei, H. K. Design Theory and Method of Neural Network Structure (National Defence Industry Press, 2005).

41. Zhang, S. \& Yin, S. Determination of in situ stresses and elastic parameters from hydraulic fracturing tests by geomechanics modeling and soft computing. J. Petrol. Sci. Eng. 124, 484-492 (2014).

42. Pei, Q. T., Li, H. B., Liu, Y. Q., Song, Q. J. \& Li, N. N. Two-stage back analysis of initial geostress field of dam areas under complex geological conditions. Chin. J. Rock Mech. Eng. 33, 2779-2785 (2014) (in Chinese).

43. Jiang, Q., Feng, X. T., Chen, J. L., Zhang, C. S. \& Huang, S. L. Nonlinear inversion of 3D initial geostress field in Jinping II Hydropower Station region. Rock Soil Mech. 11, 3003-3010 (2008) (in Chinese).

44. Xiao, M. \& Liu, Z. M. Regression analysis of 3D geostress field on Jinping secondary hydropower station. Yangtze River. 31, 42-44 (2000) (in Chinese).

45. Brown, E. T. \& Hoek, E. Technical note: Trends in relationships between measured in situ stresses and depth. Int. J. Rock Mech. Min. Sci. 15, 211-215 (1978).

46. Jing, F., Bian, Z. H., Chen, H. \& Liu, Y. K. Statistical analysis of lateral stress coefficient distribution law for different lithologys. J. Yangtze River Sci. Res. Inst. 25, 48-52 (2008) (in Chinese).

47. Goodfellow, I. et al. Generative adversarial nets. in Advances in Neural Information Processing Systems. (NIPS, 2014). https://proce edings.neurips.cc/paper/2014/hash/5ca3e9b122f61f8f06494c97blafccf3-Abstract.html

48. Mirza, M., Osindero, S. Conditional generative adversarial nets. arxiv preprint 1411.1784 (2014)

49. Odena, A., Olah, C., Shlens, J. Conditional image synthesis with auxiliary classifler GANs. arXiv preprint 1610.09585 (2016)

50. Reed, S. et al. Generative adversarial text to image synthesis. in Proceedings of the 33rd International Conference on Machine Learning. (ICML, 2016)

51. Ratlifi, L. J., Burden, S. A., Sastry, S. S. Characterization and computation of local Nash equilibria in continuous games. In Proceedings of the 51st Annual Allerton Conference on Communication, Control, and Computing (Allerton), 917-924. (IEEE, 2013)

52. Goodfellow, I., Bengio, Y. \& Courville, A. Deep Learning (MIT Press, 2016).

53. Song, Z. F., Sun, Y. J. \& Lin, X. Research on in situ stress measurement and inversion, and its influence on roadway layout in coal mine with thick coal seam and large mining height. Geotech. Geol. Eng. 36, 1907-1917 (2018).

54. Yu, Z. X., Zhou, C. B., Chen, Y. F. \& Li, J. P. Study on $v$-SVR and modified GA in back analysis of initial stress fields from displacements. Rock Soil Mech. 28, 151-162 (2007) (in Chinese).

55. Zhu, Z. Q., Sheng, Q., Zhang, Y. H. \& Leng, X. L. Three dimensional back analysis on left-bank intake slope of Longtan hydropower station. J. Yangtze River Sci. Res. Inst. 25, 33-37 (2008) (in Chinese).

56. Fang, K. T. Uniform Design and Uniform Design Table 122-124 (Science Press, 1994) (in Chinese).

57. Dai, R. \& Li, Z. K. Modified BP back analysis of 3D in-situ stresses. Chin. J. Rock Mech. Eng. 24, 83-88 (2005) (in Chinese).

58. Sun, L. J., Zhu, Y. Q., Yang, G. L. \& Yin, J. Y. Numerical simulation of ground Stress field at ends and vicinity of fault. J. Geodesy Geodyn. 29, 7-12 (2009) (in Chinese).

59. Xiao, M. \& Chen, J. T. Numerical simulation and analysis method of complex geologic faults in large underground chamber. Rock Soil Mech. 27, 880-884 (2006) (in Chinese).

60. Guo, Y. H., Zhu, W. S., Li, X. P., Jia, C. \& Li, Y. Improved regression method for initial geostress based on FLAC3D. Chin. J. Geotech. Eng. 36, 892-898 (2014) (in Chinese).

61. Yu, D. J., Yang, Z. J., Guo, Y. H., Yang, Y. G. \& Wang, B. Inversion method of initial geostress in coal mine field based on FLAC3D transverse isotropic model. J. China Coal Soc. 45, 3427-3434. https://doi.org/10.13225/j.cnki.jccs.2019.1242 (2020) (in Chinese).

\title{
Acknowledgements
}

The authors acknowledge the financial support from the National Natural Science Foundation of China (Grant number U1965203), and 'The research on support time and deformation warning of surrounding rock of large underground cavern group under extremely high stress condition of Shuangjiangkou Hydropower' (Grant number A147 SG).

\section{Author contributions}

L.Q. collected references and analyzed the measurement data, proposed the research method, and wrote this manuscript. T.Y., Z.M. and J.Z. checked the method in this manuscript and verified its feasibility. Y.L. and Z.L. carried out the measurement of ground stress in the field and processed the data. R.Z. and N.X. conceived and analysed the method of this manuscript.

\section{Competing interests}

The authors declare no competing interests.

\section{Additional information}

Correspondence and requests for materials should be addressed to Z.M.

Reprints and permissions information is available at www.nature.com/reprints.

Publisher's note Springer Nature remains neutral with regard to jurisdictional claims in published maps and institutional affiliations.

\begin{abstract}
Open Access This article is licensed under a Creative Commons Attribution 4.0 International License, which permits use, sharing, adaptation, distribution and reproduction in any medium or format, as long as you give appropriate credit to the original author(s) and the source, provide a link to the Creative Commons licence, and indicate if changes were made. The images or other third party material in this article are included in the article's Creative Commons licence, unless indicated otherwise in a credit line to the material. If material is not included in the article's Creative Commons licence and your intended use is not permitted by statutory regulation or exceeds the permitted use, you will need to obtain permission directly from the copyright holder. To view a copy of this licence, visit http://creativecommons.org/licenses/by/4.0/.
\end{abstract}

(C) The Author(s) 2021 